CLINICAL AND EXPERIMENTAL VACCINE RESEARCH

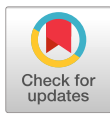

Clin Exp Vaccine Res 2019;8:116-123 https://doi.org/10.7774/cevr.2019.8.2.116 pISSN 2287-3651 • elSSN 2287-366X

Ji Hyen Hwang', Ki Hwan Kim², Seung Beom Han ${ }^{3}$, Hyun Hee Kim 4 , Jong-Hyun Kim ${ }^{5}$, Soo Young Lee ${ }^{6}$, Ui Yoon Choi ${ }^{7}$, Jin Han Kang ${ }^{1,8}$ 'Department of Pediatrics, Seoul St. Mary's Hospital, Seoul; ' 2 Department of Pediatrics, Incheon St. Mary's Hospital, Incheon; ${ }^{3}$ Department of Pediatrics, Daejeon St. Mary's Hospital, Daejeon; ${ }^{4}$ Department of Pediatrics, Uijeongbu St. Mary's Hospital, Uijeongbu; '5epartment of Pediatrics, St. Vincent's Hospital, Suwon; ${ }^{6}$ Department of Pediatrics, Bucheon St. Mary's Hospital, Bucheon; ${ }^{7}$ Department of Pediatrics, St. Paul's Hospital, Seoul; ${ }^{8}$ The Vaccine Bio Research Institute, College of Medicine, The Catholic University of Korea, Seoul, Korea

Received: July 6, 2019

Accepted: July 11, 2019

Corresponding author: Jin Han Kang, MD, PhD Department of Pediatrics, Seoul St. Mary's Hospital, College of Medicine and The Vaccine Bio Research Institute, The Catholic University of Korea, 222 Banpo-daero, Seocho-gu, Seoul 06591 Korea

Tel: +82-2-2258-6183

Fax: +82-2-537-4544

E-mail: kjhan@catholic.ac.kr

No potential conflict of interest relevant to this article was reported.

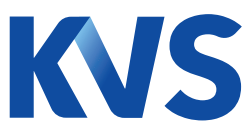

KOR E A N

VACCIN E

SO CI E T Y

(C) Korean Vaccine Society.

This is an Open Access article distributed under the terms of the Creative Commons Attribution Non-Commercial License (http://creativecommons.org/licenses/ by-nc/4.0) which permits unrestricted non-commercial use, distribution, and reproduction in any medium, provided the original work is properly cited.

\section{A clinico-epidemiological multicenter study of herpes zoster in immunocompetent and immunocompromised hospitalized children}

Purpose: There are limited population-based data regarding herpes zoster in children. Thus we conducted a multi-institutional epidemiological analysis of herpes zoster in children and comparative analysis according to their immune status.

Materials and Methods: The study included 126 children under the age of 18 years who were hospitalized for herpes zoster at 8 hospitals in South Korea, between July 2009 and June 2015. The subjects were divided into 2 groups according to their immune status, and medical records were reviewed.

Results: There were 61 cases $(48.4 \%)$ in the immunocompetent group and 65 cases $(51.6 \%)$ in the immunocompromised group. Median age was older in immunocompromised group (11.4 vs. 8.6) $(p<0.001)$. The mean duration of hospitalization was longer in immunocompromised group (11.0 vs. 6.6) $(p<0.001)$. Patients were treated with oral or intravenous antiviral agents. A total of 12 in immunocompetent group were cured only by oral acyclovir. No treatment failure was found in both groups. Six immunocompromised patients had postherpetic neuralgia and 1 case was in immunocompetent group. In immunocompetent children, herpes zoster was likely caused by early varicella infection. There was no increase in progression of severity in both groups due to appropriate treatment.

Conclusion: Early initiation of therapy is necessary for those in immunocompromised conditions. And inactivated herpes zoster vaccination may be considered in immunocompromised adolescents in the future.

Keywords: Herpes zoster, Immunocompetent children, Immunocompromised children, Epidemiological analysis

\section{Introduction}

Primary infection with varicella zoster virus (VZV) leads to the clinical manifestation of chicken pox. Following primary infection, VZV remains in the body as a latent infection in the dorsal root ganglia and cranial nerve ganglia. VZV can be reactivated when VZV-specific cell-mediated immunity becomes weak, resulting in herpes zoster accompanied by vesicular eruption along the dermatomic nerve and pain. In general, herpes zoster mainly occurs in the elderly, who exhibit low VZV-specific cell-mediated immunity, and in the immunocompromised. However, it can also occur in immunocompetent children. The clinical symptoms of herpes zoster, such as pain, pruritus, and fever, are milder in children than in adults, and complications are also less frequent 
and less severe $[1,2]$.

Epidemiological studies of herpes zoster, as well as its causes and underlying mechanisms in immunocompetent children, are relatively scarce compared to the number of studies conducted on adults. As herpes zoster appears consistently in immunocompetent children [3,4], there have been studies examining the correlation between the incidence of herpes zoster and chicken pox vaccination, in addition to some largescale population-based epidemiological studies [2,5-8], but none of these results have been validated. It is known, however, that varicella vaccination does not increase the incidence of herpes zoster and that the frequency of occurrence varies by region. In addition, it has been reported that early infection with VZV and underlying chronic disorders represent risk factors for herpes zoster in immunocompetent children $[6,9,10]$.

Although national immunization program (NIP) vaccination, including the varicella vaccine, has been required since 2005 in Korea for children over the age of 1 years, the incidences of varicella and herpes zoster have remained the same. Since the implementation of NIP vaccination, there have been no population-based epidemiological studies on herpes zoster, and systematic epidemiological studies are also lacking [11-13], as are comparative studies of herpes zoster in immunocompetent and immunocompromised children. Thus, in this study, we conducted a multi-institutional epidemiological analysis of herpes zoster in children after the introduction of chickenpox vaccination into NIP, as well as a clinical comparative analysis of immunocompetent and immunocompromised children

\section{Materials and Methods}

We recruited participants from among patients below the age of 18 who were admitted to the department of pediatrics - in 8 medical institutions (Seoul St. Mary's Hospital, St. Paul's Hospital, Incheon St. Mary's Hospital, Daejeon St. Mary's Hospital, Uijeongbu St. Mary's Hospital, St. Vincent's Hospital, Bucheon St. Mary's Hospital, and Yeouido St. Mary's Hospital) between July 2009 and June 2015. Those who were suspected to have herpes zoster due to unilateral bullous skin lesions accompanied by clinical pain received a definitive diagnosis through examination after admission into the study. Data were collected from patients' medical records, including age, sex, presence of underlying disease, history of varicella and immunization history of varicella vaccination, clinical features, examination results, treatment and progress, and complications at the time of admission. The authors assert that all procedures contributing to this work comply with the ethical standards of the relevant national and institutional committees on human experimentation (Catholic Medical Center, XC15RAMI0079) and with the Helsinki Declaration of 1975, as revised in 2008. Informed consent was obtained from all study participants.

Patients were divided into immunocompromised and immunocompetent groups according to their immune status resulting from underlying diseases. Patients receiving cancer therapy or long-term administration of steroids or immunosuppressants due to hematological tumors, solid tumors, congenital immunodeficiency, autoimmune or rheumatic immune disease, chronic kidney disease, or organ transplantation were categorized as immunocompromised. Patients who had not been diagnosed with one of these underlying diseases were categorized as immunocompetent. The progression of clinical symptoms, associated complications, and treatment outcomes regarding herpes zoster were compared between the 2 groups.

SAS for Windows version 9.4 (SAS Institute Inc., Cary, NC, USA) was used for all statistical analyses. Categorical data, such as sex ratio, distribution of mean age, manifestation rate of an associated symptom (fever), and the route of drug administration, were analyzed by chi-square test. The category, witha low expected frequency, was analyzed with Fisher exact test. Continuous data, such as mean age, days with fever, mean days of admission, blood test values, and treatment period, were analyzed with two-sample t tests. Differences were considered statistically significant at $\mathrm{p} \leq 0.05$.

\section{Results}

\section{Demographic characteristics and underlying diseases}

Among a total of 126 subjects over the seven years of the study, there were -9 cases of herpes zoster in 2009 ( 4 immunocompetent vs. 5 immunocompromised cases), 19 in 2010 (8 vs. 11), 10 in 2011 (2 vs. 8), 27 in 2012 (11 vs. 16), 19 in 2013 (10 vs. 9), 26 in 2014 ( 15 vs. 11), and 16 in 2015 (11 vs. 5). There were 61 cases $(48.4 \%)$ in the immunocompetent group and 65 cases $(51.6 \%)$ in the immunocompromised group. The male:female sex ratio was 0.79:1.0 in the immunocompetent group and 0.91:1.0 in the immunocompromised group, reflecting no significant difference in sex ratio between the 2 groups $(\mathrm{p}=0.699)$. 
The median age of the patients was 8.6 years in the immunocompetent group and 11.4 years in the immunocompromised group, which represents a significant difference between the 2 groups $(p<0.001)$. Children aged $6-10$ years were the most prevalent in the immunocompetent group (22 patients, $36.1 \%$ ), whereas those aged 11-15 years were more prevalent in the immunocompromised group (30 patients, $46.2 \%)$. Despite this, there was no significant difference between the groups in terms of age distribution $(p=0.062)$ (Table 1).

In the analysis of underlying diseases in the immunocompromised group, blood cancer was the most prevalent (52 patients, $80 \%$ ), followed by aplastic anemia (8 patients), solid tumors (3 patients), chronic Epstein-Barr virus infection (1 patient), and rheumarthritis (1 patient).

\section{Varicella disease history and varicella vaccine immunization history}

In the immunocompromised group, among the 13 patients, with known history regarding whether they had varicella zoster infection or not, 9 subjects (69.2\%) had varicella or herpes zoster. Among these, 3 patients had experienced a recurrence of herpes zoster, all of whom had received a stem cell transplant due to blood cancer. In the immunocompetent group,

Table 1. Sex and age distributions of immunocompetent and immunocompromised patients

\begin{tabular}{lcccc}
\hline Variable & $\begin{array}{c}\text { Immuno- } \\
\text { competent } \\
(\mathrm{n}=61)\end{array}$ & $\begin{array}{c}\text { Immuno- } \\
\text { compromised } \\
(\mathrm{n}=65)\end{array}$ & Total & p-value \\
\hline Sex & & & & \\
$\quad$ Male:Femalea) & $27: 34(0.79: 1.0)$ & $31: 34(0.91: 1.0)$ & $58: 68(0.85: 1.0)$ & $0.699^{b)}$ \\
Age (yr), $n(\%)$ & & & & \\
1 & $1(1.6)$ & 0 & $1(0.8)$ & \\
$1-5$ & $11(18.0)$ & $5(7.7)$ & $16(12.7)$ & \\
$6-10$ & $22(36.1)$ & $15(23.1)$ & $37(29.4)$ & \\
$11-15$ & $18(29.5)$ & $30(46.2)$ & $48(38.1)$ & \\
$16-18$ & $9(14.8)$ & $15(23.1)$ & $24(19.0)$ & \\
Mean age (yr) & 8.6 & 11.4 & & $0.001^{\text {c) }}$
\end{tabular}

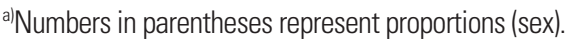

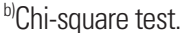

${ }^{\mathrm{c} T}$ Two-sample t test. among 27 patients, with known history regarding whether they had varicella zoster infection or not, 16 subjects (59.3\%) had varicella.

Among 107 patients who had been immunized with the varicella vaccine, 49 (45.8\%) had a confirmed immunization history of varicella: 13 out of 64 (21.3\%) in the immunocompromised group and 36 out of $43(83.7 \%)$ in the immunocompetent group (Table 2).

\section{Associated symptoms, laboratory results, and hospitalization periods}

Associated symptoms included fever, vomiting, and headache. Fever, which was the most prevalent symptom, occurred in 13 immunocompetent patients (21.3\%) and 22 immunocompromised patients $(33.8 \%)$. The mean duration of fever was 3.1 days in the immunocompetent group and 2.3 days in the immunocompromised group, whichwas not statistically significant $(\mathrm{p}=0.149)$ (Table 3$)$. In analyzing the laboratory results, we found that the mean white blood cell count was 6,210.9 cells $/ \mathrm{mm}^{3}$ in the immunocompetent group and 4,026.7 cells/ $\mathrm{mm}^{3}$ in the immunocompromised group, while the mean neutrophil counts were $3,975.7$ cells $/ \mathrm{mm}^{3}$ and 2,271.4 cells/ $\mathrm{mm}^{3}$ in the 2 groups, respectively. Both measurements were significantly different between groups $(\mathrm{p}<0.001)$. Mean C-re-

Table 3. Associated symptoms, laboratory findings, and hospitalization duration of immunocompetent and immunocompromised patients

\begin{tabular}{|c|c|c|c|}
\hline Variable & $\begin{array}{l}\text { Immuno- } \\
\text { competent } \\
(n=61)\end{array}$ & $\begin{array}{c}\text { Immuno- } \\
\text { compromised } \\
(\mathrm{n}=65)\end{array}$ & $\mathrm{p}$-value \\
\hline Fever, $\mathrm{n}(\%)$ & $13(21.3)$ & $22(33.8)$ & $0.116^{a)}$ \\
\hline Fever duration (day) & 3.1 & 2.3 & $0.149^{b)}$ \\
\hline WBC count (cells $/ \mathrm{mm}^{3}$ ) & $6,210.9$ & $4,026.7$ & $0.001^{b)}$ \\
\hline $\mathrm{CRP}(\mathrm{mg} / \mathrm{dL})$ & 1.14 & 0.74 & $0.256^{b)}$ \\
\hline ANC (cells $\left./ \mathrm{mm}^{3}\right)$ & $3,975.7$ & $2,271.4$ & $0.001^{b)}$ \\
\hline Elevated AST, ALT, n (\%) & 0 & $27(41.5)$ & $0.001^{b)}$ \\
\hline Hospitalization duration (day) & 6.6 & 11.0 & $0.001^{b)}$ \\
\hline
\end{tabular}

WBC, white blood cell; CRP, C-reactive protein; ANC, absolute neutrophil count; AST, aspartate aminotransferase; ALT, alanine transaminase.

a) Chi-square test.

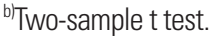

Table 2. Varicella infection and vaccination histories of immunocompetent and immunocompromised patients

\begin{tabular}{lccccc}
\hline & Chicken pox & Herpes zoster & Chicken pox vaccination & Non-vaccinated & Unknown \\
\hline Immunocompetent & 16 & 0 & 36 & 7 & 18 \\
Immunocompromised & 6 & 3 & 13 & 51 & 1 \\
\hline
\end{tabular}


active protein counts were $1.14 \mathrm{mg} / \mathrm{dL}$ in the immunocompetent group and $0.74 \mathrm{mg} / \mathrm{dL}$ in the immunocompromised group and were not significantly different between groups $(\mathrm{p}=0.256)$. No cases in the immunocompetent group exhibited increases in aspartate aminotransferase (AST) and alanine transaminase (ALT), markers for disseminative herpes zoster, while 27 (41.5\%) in the immunocompromised group did, representing a significantly higher number of patients in the immunocompromised group $(\mathrm{p}<0.001)$ (Table 3$)$. The mean duration of hospitalization was 6.6 days (4-15 days) in the immunocompetent group and 11.0 days (7-21 days) in the immunocompromised group, a difference that was significant $(\mathrm{p}<0.001)$ (Table 3$)$.

\section{Dermatomic distributions of herpes zoster skin lesions}

Herpes zoster skin lesions are distributed over 1 or more dermatomes. In the immunocompetent group, the frequency of zoster in trigeminal dermatomes was $32.8 \%$ (20 patients), followed by the thoracic dermatomes (29.5\% 18 patients), while

Table 4. Dermatomic distributions of herpes zoster skin lesions in immunocompetent and immunocompromised patients

\begin{tabular}{lccc}
\hline Dermatome & $\begin{array}{c}\text { Immunocompetent } \\
(\mathrm{n}=61)\end{array}$ & $\begin{array}{c}\text { Immuno- } \\
\text { compromised (n=65) }\end{array}$ & Total \\
\hline Cranial nerve & $20(32.8)$ & $5(7.7)$ & $25(19.8)$ \\
Cervical & $11(18.0)$ & $9(13.8)$ & $20(15.9)$ \\
Thoracic & $18(29.5)$ & $21(32.3)$ & $39(30.9)$ \\
Lumbar & $4(6.6)$ & $17(26.2)$ & $21(16.7)$ \\
Sacral & 0 & $3(4.6)$ & $3(2.4)$ \\
Multiple & $8(13.1)$ & $10(15.4)$ & $18(14.3)$ \\
\hline
\end{tabular}

Values are presented as number (\%).

Table 5. Therapeutic drugs and administration routes used to in the treatment of immunocompetent and immunocompromised patients

\begin{tabular}{lccc}
\hline & $\begin{array}{c}\text { Immuno- } \\
\text { competent } \\
(\mathrm{n}=61)\end{array}$ & $\begin{array}{c}\text { Immuno- } \\
\text { compromised } \\
(\mathrm{n}=65)\end{array}$ & $\mathrm{p}$-value \\
\hline Therapeutic drug & 60 & 62 & $>0.99^{\mathrm{a})}$ \\
ACV only & 1 & 2 & \\
IV ACV+PO famciclovir & 0 & 1 & \\
IV ACV+PO valacyclovir & & & \\
Administration route & 36 & 39 & $<0.001^{\text {b) }}$ \\
IV & 13 & 26 & \\
IV+PO & 12 & 0 & \\
PO & & & \\
\hline
\end{tabular}

IV, intravenous; ACV, acyclovir; PO, oral.

alFisher exact test.

${ }^{b}$ Chi-square test. in the immunocompromised group, the thoracic dermatomes (21 patients, 32.3\%) was the most involved followed by the lumbar dermatomes (17 patients, 26.2\%). There were 18 (14.3\%) cases involving more than 2 dermatomes, with 8 cases from the immunocompetent group and 10 cases from the immunocompromised group (Table 4).

\section{Treatment and complications}

Patients were treated with oral or intravenous antiviral agents. Among immunocompromised patients, 39 were given intravenous acyclovir only, and 26 were given both intravenous acyclovir and oral antiviral agents (acyclovir, 23; famciclovir, 2 ; valacyclovir, 1). No patient was treated only with oral antiviral agents. In the immunocompetent group, 36 patients were given intravenous acyclovir only, and 13 patients were given both intravenous acyclovir and oral antiviral agents (acyclovir, 12; famciclovir, 1). In addition, 12 patients were completely cured by oral acyclovir administration, which was a significant difference from the immunocompromised group $(\mathrm{p}<0.001)$. Failure of treatment after the administration of antiviral agents was not observed in either group (Table 5).

Regarding complications, encephalomeningitis was observed in 2 immunocompetent patients and 1 immunocompromised patient, and Ramsay Hunt syndrome was observed in 3 immunocompromised patients. A microbiologically confirmed secondary bacterial infection of surgical scarlet fever caused by Staphylococcus aureus was observed in 1 patient from the immunocompetent group. In addition, one cellulitis, keratitis, and blepharitis cases were observed in the immunocompetent group. Neuralgia was reported in 7 patients following herpes zoster infection: 6 cases from the immunocompromised group and 1 case from the immunocompetent group (Table 6).

Table 6. Complications in immunocompetent and immunocompromised patients

\begin{tabular}{lccc}
\hline Complication & $\begin{array}{c}\text { Immuno- } \\
\text { competent } \\
(\mathrm{n}=61)\end{array}$ & $\begin{array}{c}\text { Immuno- } \\
\text { compromised } \\
(\mathrm{n}=65)\end{array}$ & Total \\
\hline Meningitis & 2 & 1 & 3 \\
Ramsay hunt syndrome & 0 & 3 & 3 \\
Postherpetic neuralgia & 1 & 6 & 7 \\
Cellulitis & 1 & 0 & 1 \\
Surgical scarlet fever & 1 & 0 & 1 \\
Keratitis & 1 & 0 & 1 \\
Blepharitis & 1 & 0 & 1
\end{tabular}


Ji Hyen Hwang et al • Clinico-epidemiology of herpes zoster in children

\section{Discussion}

Herpes zoster is a disease caused by the reactivation of latent VZV following reduced virus-specific cell-mediated immunity. Although it mainly occurs in the elderly and immunocompromised, it can occur in all age groups and immune statuses. Despite regional differences, it is consistently reported in children. Hence, epidemiological study and monitoring of pediatric herpes zoster are required. Recently, studies to assess changes in herpes zoster incidence rates in children after the introduction of the varicella vaccine $[8,14,15]$, and studies about the risk factors of herpes zoster in normal children [6, 16-18] have been reported. However, epidemiological studies of herpes zoster in Korean children are still lacking.

Incidence rates of herpes zoster in children vary widely across studies, as do views on the association between herpes zoster and varicella vaccination. This partially stems from conflicting study results; for example, some studies reported an increase in the incidence of herpes zoster due to reduced natural exposure resulting from a decrease in varicella infection after the introduction of the varicella vaccine [19-21]. In contrast, other studies claimed that the incidence of herpes zoster has decreased because the latent version of the live attenuated varicella vaccine strain exhibits reduced reactivation activity compared to that of wild viruses $[22,23]$. The mean age of incidence was found to be 8 years in one report and 12 years in another, also showing variation. However, the fact that early varicella infection is associated with the incidence of herpes zoster in immunocompetent children has been accepted by most researchers $[6,17,19,24]$. Furthermore, the incidence of herpes zoster is known to be high in children without immunodeficiency but who have chronic diseases such as asthma or diabetes [25-27]. One Korean study reported that the incidence of herpes zoster in children have increased since the mid-1990s, when the varicella vaccine was introduced, and that the median age of incidence is 9.9 years [11].

We performed a retrospective study after the varicella vaccine was introduced to the routine NIP, and thus our study has certain limitations. However, we were able to confirm that the incidence of herpes zoster has remained constant in immunocompetent children. The median age at onset of herpes zoster in this study was 8.6 years in the immunocompetent patients and 11.4 years in immunocompromised patients, reflecting a significantly lower age in immunocompetent patients (Table 1). Among immunocompetent herpes zoster patients, 16 had a history of varicella infection, with 10 of these infections occurring before the age of 2 years. Hence, we speculate that the mean age was lower in immunocompetent children than in immunocompromised patients because early infection is associated with the incidence of herpes zoster in immunocompetent children. In addition, most immunocompetent children received the varicella vaccine, while immunization rates were low among immunocompromised patients (Table 2). To confirm this, a prospective, longitudinal cohort study is needed.

In terms of underlying disease states, we found that $3 \mathrm{im}$ munocompetent children had diabetes. Additionally, it has been shown that immunocompromised children, especially those with hematological malignancies and solid tumors, exhibit high incidences of herpes zoster as adults [16]. Among the 65 immunocompromised patients who participated in this study, 52 of them had hematological malignancies, and 3 had solid tumors.

In our study population, general symptoms such as fever and fatigue appeared in the early stage. Pain and pruritus of the skin lesions was the most common symptoms. In most patients, pruritus increased as the inflammation and blisters associated with skin lesions dissipated, and pain was only observed in certain immunocompromised patients. This clinical progression consist with previous study results $[28,29]$. Furthermore, postherpetic neuralgia can occur in the late stages of the disease, and therefore proper pain management is required. These typical clinical symptoms can be clearly observed in the elderly and immunocompromised adults. In children (excluding immunocompromised children in whom treatment was delayed or not given), both immunocompetent and immunocompromised patients generally exhibit mild symptoms and progression compared to adults $[28,29]$. A recent study reported significantly higher rates of associated symptoms, such as fever, pain, and pruritus, in immunocompetent children with herpes zoster than in immunocompromised ones, suggesting that the differences were related to immune status [28]. In this study, the most common symptom (excluding skin symptoms) was fever, the mean duration of which was 3 days in both groups. According to the basic blood chemistry test performed during hospitalization, total white blood cell counts and neutrophil counts were significantly higher in immunocompetent patients than in immunocompromised children. According to the liver function test, ALT and AST levels were elevated in $41.5 \%$ of immunocompromised patients. The duration of hospitalization was significantly longer in immunocompromised patients, with 
means of 6.6 days in immunocompetent children and 11.0 days in immunocompromised children. Despite these differences, low levels of segmented neutrophils and changes in liver function were reversed in the immunocompromised group within 2 weeks, and clinical severity was not associated with the duration of admission (Table 3 ).

The dermatomic distribution of the skin lesions revealed that the cranial nerve was most involved in immunocompetent children, followed by the thoracic nerve, cervical nerve, and lumbar nerve. In immunocompromised patients, the thoracic nerve was most commonly involved, followed by the lumbar nerve, cervical nerve, cranial nerve, and sacral nerve. While dermatomic involvement varies from study to study, involvement of the thoracic nerve dermatome is generally reported to be the most common [28]. In our study, 39 patients (30.9\%) exhibited thoracic nerve involvement, which is consistent with previous results. In addition, multiple nerve involvement was observed in 8 (13.1\%) immunocompetent patients and 10 (15.4\%) immunocompromised patients, reflecting no difference between the 2 groups (Table 4 ).

Before the introduction of antiviral agents and varicella zoster immunoglobulin the mortality rate of herpes zoster in immunocompromised patients was more than $7 \%$. In this regard, early treatment is important for immunocompromised patients. Owing to high individual variation in disease progression, close monitoring of organ function and viral load is required after the administration of antiviral agents [30]. In general, starting antiviral treatment within 72 hours of the manifestation of skin lesions leads to the most favorable progression and prognosis. Acyclovir is administered intravenously or orally as the primary antiviral treatment, but intravenous acyclovir treatment can also be accompanied by oral treatment with famciclovir or valacyclovir. When there is no response to primary treatment, an alternative treatment regimen involving foscarnet or cidofovir is available. In patients with impaired renal function, brivudin can also be used as an alternative antiviral agent $[29,30]$. In addition to these direct treatments, steroids can be used in parallel to alleviate pain and reduce the duration of symptoms, but it does not affect the incidence of postherpetic neuralgia. In this study, $60 \mathrm{im}$ munocompetent and 62 immunocompromised patients were treated with acyclovir exclusively. Hence, acyclovir was the most common treatment and was performed within 3 days of the manifestation of skin lesions in all patients. One patient from the immunocompetent group and 2 from the immunocompromised group were treated with acyclovir injection and famciclovir oral administration, while 1 patient from the immunocompromised group was treated with acyclovir injection and valacyclovir oral administration. Thus, the 2 groups were largely treated with similar methods. However, acyclovir was administered orally in 12 patients from the immunocompetent group and intravenously in all immunocompromised patients, thereby reflecting a significant difference in this aspect of treatment (Table 5).

Complications are generally known to occur more often and display increased severity when immunocompromised patients receive delayed or improper treatment $[15,29,30]$. However, some studies have reported that there are more complications during the early stages of the disease involving superinfected skin lesions and ophthalmic lesions in immunocompetent children than in immunocompromised patients $[16,28]$. In this study, there were also cases associated with superinfected lesions, including cases of cellulitis, surgical scarlet fever, keratitis, and blepharitis, in immunocompetent patients at the time of admission. These complications were not observed among immunocompromised patients, reflecting a difference between the 2 groups. In contrast, postherpetic neuralgia was observed in 1 immunocompetent patient and 6 immunocompromised patients, and Ramsay Hunt syndrome was observed in 3 immunocompromised patients. Moreover, 2 immunocompetent patients and 1 immunocompromised patient presented with meningitis at the time of admission (Table 6), but symptoms improved within 3 days in all 3 patients. Most patients in this study did not exhibit either severe progression or sequelae, and postherpetic neuralgia was not severe. Such positive results appear to stem from early diagnosis and treatment.

In conclusion, we found that the incidence of herpes zoster in immunocompetent children has remained consistent following the inclusion of the varicella vaccine to the NIP in Korea. In immunocompetent children with herpes zoster, the disease was likely caused by early varicella infection, with a younger age of herpes zoster incidence than among immunocompromised patients. Clinically, the mean duration of hospitalization was longer for immunocompromised patients than for immunocompetent patients, but there was no increase in progression severity or serious complications. This is likely due to proper treatment received during the early stages of skin lesion development in both groups. In the future, active management of childhood herpes zoster will require monitoring of disease incidence and epidemiological changes through a prospective cohort study. Furthermore, 
methods for preventing early varicella infection in immunocompetent children and for reducing the incidence of herpes zoster in immunocompromised children, potentially through an inactivated or subunit varicella zoster virus vaccines, should be explored.

\section{ORCID}

Ji Hyen Hwang https://orcid.org/0000-0002-0988-6878

Ki Hwan Kim https://orcid.org/0000-0001-6145-3909

Seung Beom Han https://orcid.org/0000-0002-1299-2137

Hyun Hee Kim https://orcid.org/0000-0002-7196-2894

Jong-Hyun Kim https://orcid.org/0000-0001-8641-7904

Soo Young Lee https://orcid.org/0000-0002-5354-3135

Jin Han Kang https://orcid.org/0000-0003-1610-6742

\section{References}

1. Gershon AA. Varicella-zoster virus. In: Feigin RD, Cherry JD, editors. Textbook of pediatric infectious diseases. 5th ed. Philadelphia, PA: WB Saunders Co; 2003. p.1962-9.

2. Petursson G, Helgason S, Gudmundsson S, Sigurdsson JA. Herpes zoster in children and adolescents. Pediatr Infect Dis J 1998;17:905-8.

3. Yih WK, Brooks DR, Lett SM, et al. The incidence of varicella and herpes zoster in Massachusetts as measured by the Behavioral Risk Factor Surveillance System (BRFSS) during a period of increasing varicella vaccine coverage, 1998-2003. BMC Public Health 2005;5:68.

4. Jumaan AO, Yu O, Jackson LA, Bohlke K, Galil K, Seward JF. Incidence of herpes zoster, before and after varicellavaccination-associated decreases in the incidence of varicella, 1992-2002. J Infect Dis 2005;191:2002-7.

5. Guess HA, Broughton DD, Melton LJ 3rd, Kurland LT. Epidemiology of herpes zoster in children and adolescents: a population-based study. Pediatrics 1985;76:512-7.

6. Kakourou T, Theodoridou M, Mostrou G, Syriopoulou V, Papadogeorgaki H, Constantopoulos A. Herpes zoster in children. J Am Acad Dermatol 1998;39:207-10.

7. Insinga RP, Itzler RF, Pellissier JM, Saddier P, Nikas AA. The incidence of herpes zoster in a United States administrative database. J Gen Intern Med 2005;20:748-53.

8. Wen SY, Liu WL. Epidemiology of pediatric herpes zoster after varicella infection: a population-based study. Pediatrics 2015;135:e565-71.

9. Pergam SA, Forsberg CW, Boeckh MJ, et al. Herpes zoster incidence in a multicenter cohort of solid organ transplant recipients. Transpl Infect Dis 2011;13:15-23.

10. Grote V, von Kries R, Rosenfeld E, Belohradsky BH, Liese J. Immunocompetent children account for the majority of complications in childhood herpes zoster. J Infect Dis 2007; 196:1455-8.

11. Mok HR, Park SY, Lee SY, et al. A recent 10-year clinical and epidemiological study on zoster under 20 years old. Korean J Pediatr Infect Dis 2005;12:195-201.

12. Kwak BO, Kim DH, Lee HJ, Choi EH. Clinical manifestations of hospitalized children due to varicella-zoster virus infection. Korean J Pediatr Infect Dis 2013;20:161-7.

13. Park SJ, Song HJ, Kim CW, Lee KS. A clinical study of 72 cases of herpes zoster in children and adolescents. Korean J Dermatol 2006;44:664-8.

14. Weinmann S, Chun C, Schmid DS, et al. Incidence and clinical characteristics of herpes zoster among children in the varicella vaccine era, 2005-2009. J Infect Dis 2013;208: 1859-68.

15. Lin $\mathrm{HC}$, Chao $\mathrm{YH}, \mathrm{Wu} \mathrm{KH}$, et al. Increased risk of herpes zoster in children with cancer: a nationwide populationbased cohort study. Medicine (Baltimore) 2016;95:e4037.

16. Wootton SH, Law B, Tan B, et al. The epidemiology of children hospitalized with herpes zoster in Canada: Immunization Monitoring Program, Active (IMPACT), 1991-2005. Pediatr Infect Dis J 2008;27:112-8.

17. Tseng HF, Smith N, Marcy SM, Sy LS, Jacobsen SJ. Incidence of herpes zoster among children vaccinated with varicella vaccine in a prepaid health care plan in the United States, 2002-2008. Pediatr Infect Dis J 2009;28:1069-72.

18. Civen R, Chaves SS, Jumaan A, et al. The incidence and clinical characteristics of herpes zoster among children and adolescents after implementation of varicella vaccination. Pediatr Infect Dis J 2009;28:954-9.

19. Feder HM Jr, Hoss DM. Herpes zoster in otherwise healthy children. Pediatr Infect Dis J 2004;23:451-7.

20. Brisson M, Gay NJ, Edmunds WJ, Andrews NJ. Exposure to varicella boosts immunity to herpes-zoster: implications for mass vaccination against chickenpox. Vaccine 2002;20:2500-7.

21. Thomas SL, Hall AJ. What does epidemiology tell us about risk factors for herpes zoster? Lancet Infect Dis 2004;4:2633.

22. Tanuseputro P, Zagorski B, Chan KJ, Kwong JC. Population-based incidence of herpes zoster after introduction of a publicly funded varicella vaccination program. Vac- 
cine 2011;29:8580-4.

23. Chen JJ, Zhu Z, Gershon AA, Gershon MD. Mannose 6-phosphate receptor dependence of varicella zoster virus infection in vitro and in the epidermis during varicella and zoster. Cell 2004;119:915-26.

24. Huang JL, Sun PC, Hung IJ. Herpes zoster in infancy after intrauterine exposure to varicella zoster virus: report of two cases. J Formos Med Assoc 1994;93:75-7.

25. Kim BS, Mehra S, Yawn B, et al. Increased risk of herpes zoster in children with asthma: a population-based casecontrol study. J Pediatr 2013;163:816-21.

26. Umaretiya PJ, Swanson JB, Kwon HJ, Grose C, Lohse CM, Juhn YJ. Asthma and risk of breakthrough varicella infection in children. Allergy Asthma Proc 2016;37:207-15.
27. Hata A, Kuniyoshi M, Ohkusa Y. Risk of herpes zoster in patients with underlying diseases: a retrospective hospital-based cohort study. Infection 2011;39:537-44.

28. Kuchar E, Szenborn L, Lis I, Jaroszewska A, Czeladzka J. Clinical presentation of herpes zoster in immunocompetent and immunocompromised hospitalized children treated eith scyclovir. J Pediatr Hematol Oncol 2016;38: 394-7.

29. Gross G, Schofer H, Wassilew S, et al. Herpes zoster guideline of the German Dermatology Society (DDG). J Clin Virol 2003;26:277-89.

30. Wiegering V, Schick J, Beer M, et al. Varicella-zoster virus infections in immunocompromised patients: a single centre 6-years analysis. BMC Pediatr 2011;11:31. 